\title{
Cátedra e Hegemonia da Prática Docente na Faculdade de Medicina da Universidade Federal de Minas Gerais
}

\author{
Léa Pinheiro Paixão \\ Universidade Federal Fluminense (UFF)
}

Apresenta restiltados de estudo empírico. A partir da análise de depoimentos de ex-catedráticos da Faculdade de Medicina da Universidade Federal de Minas Gerais, são fornecidos elementos para explicar a rejeição à cátedra que emergiu no interior da própria universidade. São explorados conflitos que opunham catedráticos/médicos a catedráticos/pesquisadores no campo acadêmico, considerado como campo de lutas de natureza simbólica.

\section{Introdução}

A compreensão da rejeição à cátedra, que se deu no interior da própria universidade e que precedeu a implantação da reforma legal e da reforma consentida, não se completa sem a análise dos conflitos de natureza simbólica, decorrentes de interesses propriamente acadêmicos em oposição naquele momento.

O campo acadêmico, como outros campos simbólicos, é um campo de luta, luta que opõe interesses de ordem simbólica. A lógica dessa luta é aparentemente neutra e autônoma. Aparentemente, porque, na verdade, essa autonomia é relativa, já que a lógica que baliza as lutas no campo simbólico articula-se às lutas que se inscrevem nas relações sociais mais amplas. 
O universo puro da ciência mais pura é um campo social como qualquer outro, com suas relações de força e seus monopólios, suas lutas e suas estratégias, seus interesses e seus lucros, mas onde todas essas invariantes revestem-se de formas específicas (Bourdieu, 1975, p.91).

Nessa perspectiva, a reorganização da universidade proposta pela reforma foi objeto de disputa, opondo interesses acadêmicos hegemônicos e interesses acadêmicos emergentes, que procuravam impor-se.

O modelo organizacional da universidade moderna proposto pela reforma respondia à demanda de um grupo de catedráticos. A ele se opunha outro grupo de catedráticos. Separava-os interesses de ordem acadêmica e a perspectiva que tinham de universidade.

Analisando entrevistas realizadas com ex-catedráticos, nãocatedráticos, ex-alunos de catedráticos da Universidade Federal de Minas Gerais (UFMG), a importância da luta simbólica na implantação da reforma mostrou-se evidente ${ }^{1}$. A compreensão dessa luta se impôs como explicação das diferenças de opinião sobre cátedra observadas entre antigos catedráticos da Faculdade de Medicina. Essa unidade foi núcleo de tensões especiais no processo de implantação da reforma.

$\mathrm{Na}$ Faculdade de Medicina, como se verá a seguir, as tensões foram produzidas pela oposição de interesses simbólicos entre catedráticos/médicos e catedráticos/pesquisadores.

Os catedráticos/médicos que se ocupavam das cadeiras do ciclo profissional identificavam-se, de forma prioritária, com a formação profissionai e, conseqüentemente, com a graduação.

\footnotetext{
${ }^{1}$ A pesquisa realizada na Universidade Federal de Minas sobre a cátedra contou, na fase das entrevistas, com a participação da professora Maria Gislaine Damasceno e das auxiliares de pesquisa I vete Diniz e Maria Júlia Carvalho. Além das entrevistas realizadas para esta pesquisa, na análise foram utilizadas sete entrevistas realizadas no projeto coordenado por Laura da Veiga, a quem agradeço. O resultado dessa pesquisa encontra-se em artigo publicado (Veiga et al, 1987). A análise aqui apresentada foi realizada no decorrer de minha visita à Universidade do Canadá francês. Pude, então, manter contatos que me foram úteis com o professor Ives Gingras, da Universidade do Québec e Montréal (UQAM), e Pierre Dandurand, da Universidade de Montreal. Agradeço a ambos sua disponibilidade para me receber, e ao $\mathrm{CNPq}$, que propiciou minha viagem ao Canadá.
} 
Os catedráticos/pesquisadores, responsáveis pelas cadeiras básicas, construíram sua identidade, tendo como referência a prática de pesquisa, que os remetia para articulações fora da faculdade e os levava a priorizar a formação de novos pesquisadores, objeto do ensino de pós-graduação.

$\mathrm{Na}$ Faculdade de Medicina, a cátedra realizara-se, de forma plena, no interior do ciclo profissional, ou seja, entre os catedráticos/médicos. A criação da faculdade decorrera da mobilização de médicos e se organizara em torno do objetivo de formação desses profissionais. A criação da universidade, em 1927, expressava demandas do grupo fundador, preocupado com a consolidação da instituição e, por isso, sua organização refletia interesses da prática docente e da cátedra.

Alterações ocorridas na prática docente, decorrentes da adoção de novo modelo de medicina, com o estímulo da Fundação Rockfeller, propiciaram a emergência da prática de pesquisa e novos agentes foram sendo formados para essa prática.

Os novos agentes e o fortalecimento institucional da prática de pesquisa geraram tensões entre professores/médicos e professores/ pesquisadores, entre cátedras de área básica e cátedras da área profissional.

Na busca da hegemonia, os agentes da prática emergente articularamse propondo nova estrutura, em que a prática de pesquisa fosse hegemônica - o Instituto Central de Biologia (ICB). Nessa luta, a velha estrutura identificase com a cátedra, e a defesa da reforma supõe sua extinção.

O relato do conflito entre as cátedras da área básica e as cátedras da área profissional, na Faculdade de Medicina, ajuda a compreender as dificuldades da implantação do ICB na UFMG, que só ocorreu em decorrência de imposição legal.

\section{A cátedra no ensino médico - hegemonia da prática docente}

A Faculdade de Medicina foi fundada em 1911, por médicos da Associação Médico-Cirúrgica de Minas Gerais, articulada ao projeto de 
fração da elite política que promovera a mudança da capital mineira para Belo Horizonte. Oposições foram enfrentadas. De um lado, provenientes de outras frações da elite dominante, que desejariam ter suas cidades, mais tradicionais, como sede da nova faculdade. De outro lado, a nova faculdade teve a oposição da Faculdade de Medicina do Rio de Janeiro. Sua consolidação realizou-se gradualmente, tendo como etapas a equivalência do curso, a oficialização da faculdade e sua federalização. Nessa trajetória, a congregação, núcleo de poder, constituída inicialmente dos médicos fundadores, ampliou-se de forma controlada. Nascida umbilicalmente ligada à associação profissional, o currículo dos cursos, os objetivos da faculdade e a lógica organizadora de suas atividades refletem os interesses e as percepções de profissionais da Medicina.

\section{PRÁTICA PEDAGÓGICA E CURRÍCULO OCULTO}

O modelo de ensino médico implantado na Faculdade de Medicina, influenciado pela Faculdade de Medicina do Rio de Janeiro, onde se haviam formado os fundadores, seguia a orientação francesa de Medicina. A Medicina era concebida como arte, e a relação direta médico-paciente constituía-se no núcleo do tratamento. Baseado nas informações coletadas nessa relação, o médico elaborava seu diagnóstico. Trata-se de uma concepção holística, diferente da concepção "científica", de especialização, a qual foi mais tarde implantada na faculdade, sob influência americana. A competência no quadro da Medicina-Arte adquiria-se, principalmente por meio da experiência, do acompanhamento de casos e do contato com médicos mais velhos gabaritados. $\mathrm{O}$ contato com as ciências, com os laboratórios que já existiam, não alterava a perspectiva holística daquela abordagem, conforme o testemunho de Nava:

Quando ine iniciei no estudo da clínica, há cinqüenta e três anos, o auxílio do laboratório e dos raios $\mathrm{X}$ era incipiente, de modo que nossa semiologia fisica tinha de ser levada às últimas conseqüências. Tínhamos de aprender 
a conversar bem com o doente, a olhá-lo melhor, a apalpá-lo, percuti-lo e auscultá-lo com um capricho que as gerações atuais desprezam ou ignoram (Nava, 1985, p.204).

A alteração no eixo de influência, da França para os Estados Unidos, teve repercussão importante na história da faculdade e favoreceu a emergência da pesquisa biológica em Belo Horizonte.

No período de influência francesa, a Faculdade de Medicina teve como aluno Pedro Nava, cujas memórias, já citadas, permitem reconstituir o currículo, as práticas pedagógicas e o espírito que animava a escola e os alunos da época. Ele seguiu curso no período de 1921 a 1927, tendo repetido o primeiro ano. É interessante resumir sua trajetória, para se ter idéia do curso.

Nava, que perdera o pai, teve cedo de conciliar seus estudos com o trabalho no Departamento de Higiene, obtido por meio das relações familiares. Estudioso, aplicado, ele explica sua repetência na primeira série como

... legalissima no ponto de vista dos juizes da época e do (Inquinilo, quando era obrigação do professor enredar o aluno, confundi-lo e acuá-lo até a bomba - era, no meu, injustiça e clamorosa porque eu tinha estudado e sabia a matéria (p.23).

Ele considerava o ensino nas cadeiras básicas "bem seguido" e descreve minuciosamente as atividades desenvolvidas em algumas delas. $\mathrm{Na}$ cadeira de Anatomia, por exemplo, as aulas teóricas eram dadas no anfiteatro, diante de um cadáver e de exemplares de ossos. O professor fazia preleções a partir de um manual francês (Testut), "que ele tinha de cor e salteado". Ao sinal que anunciava o fim da aula, o professor interrompia a preleção para retomar do mesmo ponto na aula seguinte. Nava e os colegas estudavam no manual indicado pelo professor, manuseando material (ossos) que ficava disponível para os alunos no gabinete de Osteologia.

Nava foi monitor voluntário em duas cadeiras: a de Química, em 1922, e a de Anatomia Patológica, em 1925. Como monitor, cabia-lhe colaborar na preparação de cadáveres para as aulas. 
Como voluntário também, Nava pensou em se integrar à equipe do catedrático da Primeira Enfermaria de Clínica Médica no terceiro ano do curso, mas foi dissuadido disso:

Desde meu primeiro ano médico, empregava as horas de folga material para ir às enfermarias da Santa Casa sobrar como turista. Olhava de longe e com inveja os professores, assistentes e internos manipulando os doentes nas salas de Werneck, Libânio, Borges, Balena, Otaviano e Aleixo. Na de Borges da Costa tive minha caraira inaugural diante do sangue e da crueza do ferro, vendo o Cavalcanti (ainda segundanista) arrancar duas unhas encravadas dos dedões do nosso amigo João Las Casas. Apreciava, principalmente, pelo número de freqüentadores, pela impecabilidade dos aventais do chefe e por sua solenidade - o Serviço da Primeira Enfermaria do Professor Alfredo Balena. Chegado ao terceiro ano tive desejos de ingressar nele e fui pedir ao excelente Dr. Abílio de Castro apresentação àquele mestre. O Dr. Abílio, com os melhores argumentos, dissuadiu-me disso. Deu-me as primeiras explicações sobre a rivalidade de putas, a coisa terrível que são o ciúme médico e a invidia medicorum pessima. Explicou-me como funcionavam e governavam nossa profissão esses baixos sentimentos e demonstrou-me que eu, traballando na Higiene, ficaria pessimamente colocado se não procurasse introduzir-me no serviço do meu Diretor que era a Segunda Enfermaria de Clínica Médica da Santa Casa. Ele mesmo encarregar-se-ia de dar uma palavra ao Samuel. Deu, e no dia seguinte trouxe a resposta. Sim. Eu poderia ingressar no serviço como interno - mas voluntário - e que podia ír me entender com seu substituto c primo, o Professor Marcelo dos Santos (Nava, 1985, p.202).

Nava integrou-se como interno voluntário à Segunda Enfermaria. Em suas Memórias, ele faz questão de explicar o porquê do voluntariado:

Grifei acima meu título de voluntário do internato porque os efetivos eram escolhidos entre alunos mais ou menos ligados ao establishment. Entre eles, um ou outro já destinado cedo à assistência efetiva, à sucessão nas cátedras. Esse ou aquele voluntário conseguia, às vezes, transpor o muro — por real valor, por muita habilidade, ou por aliança. Aliás, esse quadro é o de todas as faculdades de medicina e está na definição de quase todas as grandes carreiras médicas. É sancionado no "Juramento de Hipócrates", quando se promete ensinar os segredos da Arte só aos próprios filhos, aos dos mestres, aos vinculados por um compromisso - a nenhum outro (Nava, 1985, p.329). 
Todavia, a possibilidade de integrar a equipe de um serviço, ainda que como voluntário, teve, em sua avaliação, um papel fundamental:

Graças a Ari Ferreira escapei dessa Orfandade que é o autodidatismo no terreno médico e por sua mão adquiri lugar numa Escola, numa corrente de pensamento internístico que era a sua, a de seu pai e mestre, o grande Cícero Ferreira - que se alinha com Francisco de Castro, Miguel Couto, Almeida Magalhães, Eduardo de Menezes, entre os mais preclaros alunos de Torres Homem. Agradeço a Ari Ferreira a outorga que ele me fez, com seus ensinamentos - de uma subida linhagem espiritual (Nava, 1985, p.330).

Chama a atenção, neste trecho, o emprego, por um profissional de literatura, de dois termos: autodidatismo e escola. Ele conseguiu escapar do autodidatismo não pela realização do curso de Medicina, mas pela integração do serviço na cátedra, então dirigida por Ari Ferreira. Foi o serviço que constituiu a verdadeira escola. A palavra escola, utilizada por Nava, foi, com muita freqüência, entre entrevistados, também empregada para qualificar o trabalho desenvolvido em uma cadeira de "sucesso". Na Medicina, a verdadeira cadeira se reconhece por sua capacidade de constituir uma "escola" formadora de profissionais dotados de práticas que os distinguem.

Ao final do curso, Nava, que já estabelecera bons contatos e freqüentava a enfermaria de Werneck, obteve dele a promessa de engajálo como interno. Isso significaria um salário mais alto do que ele recebia na Higiene. Nava pediu demissão do cargo, mas, em decorrência de malentendido e da instabilidade de Werneck, não só não foi engajado como interno, como correu risco de não obter o diploma.

A trajetória de Nava e sua análise dos acontecimentos apontam para alguns aspectos que merecem ser explicitados.

Em primeiro lugar, a importância que assumia, no currículo, a passagem pelas equipes que se encontravam mais próximas do catedrático. No limite, poder-se-ia dizer que a verdadeira aprendizagem se fazia nos 
serviços ou nas atividades que reuniam alguns alunos. Sem essa escola, o médico seria autodidata. A possibilidade de entrada nessa parte do currículo era restrita a alguns alunos que detinham capital econômico, cultural ou social. Nava, que nunca se tornou efetivo dos serviços, como se pode deduzir pela leitura de suas memórias, apesar de não deter capital econômico, podia contar com o apoio do largo círculo de amizades (capital social) que sua família já estabelecera. Por isso, ele encontrou alguém como o Dr. Abílio de Castro, que o iniciou na lógica que organizava o campo acadêmico e que possibilitou sua entrada, como voluntário, é verdade, em um serviço.

No currículo regular, as cadeiras profissionais contavam, quase sempre, com uma parte teórica e outra, prática, mas a prática se limitava, na maioria das cadeiras, à demonstração. Os alunos assistiam aos exames que eram realizados pelos professores e seus assistentes, ouviam preleções a partir do caso e respondiam a questões. A existência da parte prática dependia, evidentemente, da existência de serviço na cadeira; na de Medicina Externa, como a cátedra não dispunha de serviço, Zoroastro Viana Passos só dava aulas teóricas.

A prática, a verdadeira prática, acontecia nos serviços. Nos hospitais, como internos, os alunos podiam aprender, na prática, com os catedráticos. Essa era a prática mais adequada à iniciação na MedicinaArte. A passagem pelo serviço de um catedrático conceituado facilitava sua inserção futura no campo profissional como médico. Dali também saíam, com freqüência, novos professores da faculdade.

Como se vê, o currículo do curso de Medicina não era o mesmo para o grupo de alunos. A parte prática constituía um currículo oculto, que desempenhava, no entanto, papel fundamental não só no processo de formação profissional para os que a ele tinham acesso, mas, também, e talvez principalmente, pela possibilidade de relações próximas com a equipe do catedrático, que funcionava como facilitador de engajamentos profissionais no futuro. A adoção pelo catedrático, em geral, detentor de poder no campo médico, era fundamental para o sucesso na carreira. 


\section{Emergencia da prática de pesquisa na Faculdade de Medicina}

O modelo de Medicina adotado pela Faculdade de Medicina ao tempo de Nava aluno foi sendo, aos poucos, rejeitado, em beneficio de outro, de inspiração americana, "científico". No novo modelo, a concepção de Medicina é diferente da concepção do modelo francês. A MedicinaArte foi sendo substituída pela Medicina-Ciência. Nessa nova concepção, o médico não pode se contentar em fazer diagnóstico de problema do paciente pelos sintomas e sinais exteriores que detecta na relação direta. Ele se empenha em compreender as causas gerais e, para isso, precisa de informações, obtidas através de análises de laboratório. Essa medicina científica obrigou, conseqüentemente, a uma reavaliação da contribuição do conteúdo das disciplinas básicas do currículo.

Na Faculdade de Medicina, a adoção de novo modelo de Medicina se fez sob a influência americana e contou com o estímulo da Fundação Rockfeller ${ }^{2}$.

Estimulando o desenvolvimento de atividades de pesquisa nas cadeiras básicas, a adoção do novo modelo de Medicina propiciou a emergência de condições institucionais favoráveis à pesquisa biológica.

$\mathrm{Na}$ verdade, desde sua criação, a Faculdade de Medicina contou, em seu corpo docente, com professores-pesquisadores. Foi, porém, com a mudança do modelo orientador que a atividade de pesquisa assumiu outro estatuto, inscrita, então, no conceito de Medicina e na formação do médico, como fundamental.

Entre os primeiros professores-pesquisadores, estavam: Ezequiel Dias (concunhado de Oswaldo Cruz e fundador da filial de Manguinhos em Belo Horizonte); Carlos Pinheiro Chagas (bolsista da Fundação Rockfeller, em 1917, tendo realizado, em 1923, curso nos Estados

\footnotetext{
${ }^{2}$ A Fundação Rockfeller desempenhou papel importante na implantação da Medicina dita cientifica no Brasil, via destinação de recursos que financiaram o estágio de professores nos Estados Unidos, a aquisição de material de ensino e a complementação salarial, a qual permitiu a introdução do tempo integral. A atuação daquela instituição foi objeto de estudos que buscam analisar as funções cumpridas por ela no campo médico. A título de exemplo, ver Brown (1979 e 1981) e Kohler ( 1987).
} 
Unidos); Otávio Coelho Magalhães (pesquisador, discípulo de Dias, com vários trabalhos publicados), Eurico de Azevedo Vilela (antigo colaborador de Oswaldo Cruz, que trabalhava em Manguinhos, no Rio de Janeiro; abria o curso em sua cadeira em Belo Horizonte, onde permanecia de 15 a 30 dias, e depois retornava ao Rio, deixando em seu lugar o assistente).

A virada, porém, em termos do modelo de Medicina, teve um grande estímulo por parte de um catedrático — José Baeta Viana.

\section{BAETA VIANA, O MUTANTE}

Baeta Viana foi empossado no cargo de professor substituto de Química Médica, após concurso, em 1923. Em 1925, assumiu a cátedra de Química Orgânica e Biológica e, em 1934, a de Física Biológica (Campos, 1961 ). Após passagem pelos Estados Unidos, tornou-se defensor ardoroso da perspectiva científica na Medicina e atuou na Faculdade de Medicina de Belo Horizonte para implantá-la. Baeta Viana dividia as opiniões na faculdade, opondo baetistas a não baetistas, ou seja, os defensores do novo modelo a seus críticos.

Nava, contrabaetista, refere-se a Baeta Viana nos seguintes termos:

Foi mais ou menos por esta época que o clube (Belo Horizonte) começou a ser freqüentado por José Baeta Viana, professor da Faculdade de Medicina, que eu pegara no primeiro ano como preparador da cadeira de Química. Como ele fosse muito dado, conversado e amigo dos moços, nossa roda tratou de acolher a simpática figura. Nesse tempo ele estava às voltas com a fundação de uma Biblioteca na Faculdade de Medicina e tinha conseguido espaço para instalá-la, no porão, embaixo das salas onde funcionava e Microbiologia. Vi suas primeiras estantes, os primeiros livros que por donativo foram começar a enchê-las. Muitos exemplares do Testut, do Gley, do Branca, do Mathias Duval, do Clianternesse e Podwyssotsky - descarregados de suas casas por médicos e professores que queriam se ver livres desses cartapacios veneráveis. Também as primeiras revistas e livros americanos que iam auxiliar o Baeta a trabalhar em favor do pragmatismo que ele conseguiu implantar na mentalidade de seus sequazes. Seus alunos passavam por verdadeira bourrage 
de crâne nas aulas de Química onde se aprendia exemplarmente a matéria e também a execrar a Europa e sua decadência, a admirar superlativamente os Estados Unidos e sua onisciência. Também ele fazia um trabalho de cupim ou de coral - às avessas para desmontar nossas concepções sobre a parte prática da Medicina - a clínica - que ele mostrava como amontoado de erros, para só dar valor ao que podíamos ter da Química, da Física, da Microbiologia e da Anatomia Patológica. Sob sua orientação se formaram vários cientistas (Nava, 1984, p.317).

Baeta Viana, formado na Medicina-Arte, não foi ele próprio um cientista. Não realizou pesquisa, mas, adotando as novas idéias após viagem aos Estados Unidos, sob os auspícios da Fundação Rockfeller, implantou, em sua cadeira, prática pedagógica que promoveu a formação de agentes diferentes daqueles até então produzidos pela Faculdade de Medicina. Orientou, como disse Nava, a formação de pesquisadores, tanto na área básica, como na área profissionai.

O catedrático Romeu Cançado descreveu a prática pedagógica na cadeira de Baeta Viana.

(...) no segundo ano (1923) trabalhei no laboratório do professor Baeta Viana, que era bioquímico e lá fiquei muito tempo; fui monitor. No princípio eu era voluntário (...) embora não o fosse oficialmente, ele era professor de tempo integral; ele ia lá de manhã, à tarde e à noite. Eu entrei para o laboratório de bioquímica - os alunos que se interessavam acabavam se congregando em torno dele. Ele distribuía assuntos para estudo. A mim ele deu o estudo das proteínas no sangue. A gente montava o método de dosagem, trabalhava o dia inteiro no laboratório (...) ele fez ali uma verdadeira escola bioquímica (...) muitos professores de bioquímica saíram dali (Romeu Cançado).

\section{PESQUISA NAS CADEIRAS DE CLÍNICA}

Influenciada por Baeta Viana, a clínica torna-se científica. Um dos primeiros catedráticos a organizar a prática pedagógica com a nova orientação foi Romeu Cançado. Para alguns entrevistados, ele pode ser 
considerado o pai da pesquisa clínica na Faculdade de Medicina de Belo Horizonte. Cançado iniciou o curso de Medicina em 1932. Trabalhou enquanto aluno com Baeta Viana, como voluntário e como monitor. Após a conclusão do curso, montou, com mais três baetistas, um laboratório. Também em colaboração redigiu um manual que, provavelmente, contribuiu para a difusão das novas idéias. Trata-se de um manual sobre "Métodos de laboratório aplicados à clínica teórica e interpretação". Iniciou carreira acadêmica como assistente voluntário na cadeira de Clínica. Em 1944, fez concurso para livre-docência na cadeira de Terapêutica. Em 1948, fez nova livre-docência, desta vez na cadeira de Clínica Médica. Em 1948, foi titular dessa cátedra, por meio de concurso. Em sua cadeira, Cançado sucedeu a Olinto Meirelles, um dos fundadores da Faculdade de Medicina. Até então sua cadeira não contava com serviço. Por isso, o ensino era mais teórico. Cançado pleiteou e obteve, para cadeira, uma enfermaria no Hospital São Vicente. A enfermaria foi inaugurada em 1949 na presença do governador do Estado, Juscelino Kubitscheck, ex-aluno da Faculdade de Medicina e contemporâneo de Nava. Cançado organizou, então, sua cadeira, constituindo equipe de alunos e assistentes que se interessavam pelo estudo da clínica. Sua cadeira constituiu verdadeira "escola de clínica".

Nessa cadeira, o conteúdo da disciplina era desenvolvido em aulas teóricas e aulas práticas para todo o grupo de alunos inscritos. Nas aulas teóricas, Cançado e, mais tarde, os assistentes faziam preleções, sendo os assuntos tratados de "maneira doutrinária". Nas aulas práticas, os alunos eram divididos em grupos de 20, coordenados pelos assistentes. Nelas, em geral, eram apresentados casos. Após a apresentação, seguia-se a discussão.

Os alunos internos tinham conhecimento mais aprofundado dos casos apresentados nas aulas práticas, porque os acompanhavam na enfermaria.

A equipe de Cançado era constituída de professores assistentes, assistentes voluntários, internos (alunos do $5^{\circ}$ e $6^{\circ}$ anos) e residentes (escolhidos entre os internos). Cada estudante seguia de perto um dos casos da enfermaria, que contava com 28 leitos. O paciente, ao ser 
internado, era examinado pelo interno, que discutia, depois, suas observações com o assistente responsável pelo leito. Os casos mais interessantes eram, depois, apresentados à equipe em reuniões: o aluno apresentava o caso, o assistente o comentava e, depois, todos o discutiam.

A cadeira de Cançado contava com o trabalho do laboratório localizado próximo. Ele considerava o laboratório "base fundamental" ao trabalho na cadeira. Havia integração entre sua cadeira, o laboratório e a cadeira de Anatomia Patológica, do professor Bogliolo. Reuniões de discussão eram realizadas com essa cadeira básica, onde eram analisados casos de pacientes falecidos. O grupo de Cançado apresentava as informações coletadas sobre o caso do paciente falecido e o grupo de Bogliolo relatava o resultado das análises que realizara.

Segundo Cançado, a integração com o laboratório permitiu a descoberta de uma doença até então ignorada - o calazar.

\section{PESQUISA NAS CADEIRAS BÁSICAS}

Nas cadeiras básicas, como já foi apontado, a prática de pesquisa antecede a emergência do modelo científico de Medicina. As relações de professores com a pesquisa que se realizava no Instituto de Manguinhos e em sua filial em Belo Horizonte traziam para dentro da faculdade, com certeza, preocupações de ordem científica, ou, mais precisamente, com o avanço do conhecimento na área de Biologia.

Formado em contato com esses cientistas, o professor Amílcar Viana Martins, catedrático de Parasitologia, desempenhou papel importante no desenvolvimento da prática científica na Faculdade de Medicina e na universidade.

Como outros pesquisadores, Amílcar Viana Martins, apesar de diplomado pela Faculdade de Medicina, nunca exerceu a profissão de médico, a não ser em curto período, durante a $2^{\mathrm{a}}$ Guerra. A escolha do curso de Medicina foi conseqüência da falta de opção mais adequada, no 
ensino superior de então, e seus interesses. Se Cançado fez escola na Clínica, Martins fez escola na Parasitologia.

Martins formou-se em 1929, tendo, em seguida, aceitado convite para ser assistente na cadeira de Fisiologia, de Otávio Coelho de Magalhães (pesquisador). Em 1932, também a convite, foi ser assistente na cadeira de Histología (Carlos Pinheiro Chagas). Foi primeiro catedrático na Escola de Farmácia. Em 1938, por concurso, assumiu a cátedra de Parasitologia na Faculdade de Medicina. Durante sua vida atuou em órgãos de pesquisa fora da universidade: foi diretor do Instituto Nacional de Endemias Rurais, presidente da Sociedade de Parasitologia do Brasil e da Sociedade de Biologia de Minas Gerais.

A orientação que Martins dava ao ensino em sua cátedra contribuiu para a formação de uma nova geração de profissionais, que se definiam, prioritariamente, como pesquisadores. Martins desempenhou papel central nas articulações para a fundação do Instituto Central de Biologia. Bem aceito pelo grupo hegemônico da Faculdade de Medicina, ajudou a fundar a Faculdade de Filosofia ( 1939) em que a pesquisa biológica pôde começar a se desenvolver de forma autônoma.

Em outro subcampo da Biologia, a influência direta de Baeta Viana se fez sentir na Bioquímica. Um grupo de ex-alunos da faculdade, influenciados por Baeta, formados no espírito científico, deslocaram-se para São Paulo. Buscavam lá oportunidades como pesquisadores, o que, segundo sua avaliação, não encontravam em Belo Horizonte. Em São Paulo, eles atuaram na segunda metade da década de 40 e na década seguinte, em pesquisa (Instituto Biológico de São Paulo, Faculdade de Medicina de Ribeirão Preto, USP). A Faculdade de Medicina de Ribeirão Preto foi a pioneira na articulação ensino/pesquisa no campo médico e a primeira a adequar seu currículo aos padrões norte-americanos.

Desse grupo que foi para São Paulo, dois retornaram a Belo Horizonte no início dos anos 60. Esse retorno de ex-bolsistas da Rockfeller, estimulados pela fundação, visava ao reforço do ensino/pesquisa nas cadeiras básicas. Os dois eram, naquele momento, pesquisadores de competência reconhecida no campo da Biologia. 
Carlos Diniz, ex-aluno de Viana e ex-bolsista da Fundação Rockfeller, que trabalhava na Faculdade de Medicina de Ribeirão Preto, foi convidado pelos catedráticos Versiani e Bogliolo a voltar a Belo Horizonte, a fim de assumir a coordenação de uma equipe de pesquisadores, organizada por Baeta Viana, os quais deveriam chegar de um período de bolsa nos Estados Unidos. Diniz deveria substituir Viana, o qual se aposentara, pelo período de um ano, garantindo a estruturação da equipe.

Ao assumir suas funções, Diniz percebeu que já havia, em Belo Horizonte, condições institucionais para o desenvolvimento da pesquisa em Bioquímica. Segundo suas palavras, para que o campo se fortalecesse, era necessária a extinção da cátedra e a criação do departamento.

$\mathrm{O}$ outro cientista que aceitou o convite para retornar a Belo Horizonte foi Wilson Beraldo (ex-bolsista da Rockfeller). Disposto a passar um ano na Universidade de Minas Gerais, Beraldo assumiu a cadeira de Fisiologia, cujo titular se aposentara. O convite foi formulado por um representante da Fundação Rockfeller, que se dispôs a reequipar o laboratório da cadeira em três meses.

Assim, no início da década de 60, sob os auspícios da Fundação Rockfeller e com o reforço de pesquisadores reconhecidamente experientes e respeitados, a pesquisa nas cadeiras básicas se consolida. $\mathrm{O}$ currículo do curso havia-se adequado aos novos padrões, com a introdução da disciplina Metodologia Científica, a pedido dos alunos, em 1959. A língua inglesa tornou-se obrigatória no exame vestibular. O tempo integral já existia em cadeiras básicas, desde meados da década de 50 com recursos da Rockfeller.

A prática de pesquisa, prática heterodoxa, emerge na trajetória da Faculdade de Medicina, em busca de sua consolidação, em decorrência de alterações no campo específico do ensino médico. No início, essa prática é bem assimilada (apesar de não deixar de gerar tensões), enquanto assume papel secundário na estrutura curricular e institucional. Com o fortalecimento, no entanto, dos agentes da nova prática, no interior da instituição - Faculdade de Medicina e outras da universidade — as tensões gerarão mudanças. 


\section{Emergencia da Biologia como disciplina na UFMG}

A compreensão dos conflitos que se desenhavam na Faculdade de Medicina exige uma referência à emergência da Biologia como disciplina na universidade mineira.

A pesquisa biológica já existia no Brasil antes de se constituir como campo de estudo autônomo na universidade. Como aconteceu em outros campos da produção científica, a prática de pesquisa existia antes de se incorporar como prática universitária.

No começo do século, nas faculdades de Medicina existentes, a do Rio de Janeiro e a da Bahia, a tradição clínica existente afastara dos currículos o interesse pela pesquisa.

A primeira instituição de sucesso de pesquisa biológica no Brasil foi o instituto criado em Manguinhos (Instituto Soroterápico Municipal), no Rio de Janeiro, que mais tarde assumiu o nome de Oswaldo Cruz, que o dirigiu. $\mathrm{O}$ instituto foi legalmente reconhecido como instituição de pesquisa em 1907.

Segundo Stepan (1976), o Instituto de Manguinhos sob a direção de Oswaldo Cruz e, depois, de Carlos Chagas, foi responsável pelo fato de esse ramo de pesquisa ser um dos que mais se desenvolveu no campo científico no Brasil. O esforço do instituto fez-se de forma relativamente isolada das faculdades de Medicina existentes. Oswaldo Cruz defrontavase com a escassez de pesquisadores, mas conseguiu organizar sua equipe de trabalho no próprio instituto, com jovens formados em Medicina. Ele próprio, também, formou-se em medicina em 1892, e foi preparador da cadeira de Higiene, enquanto aluno. No início da carreira dedicou-se à clínica, mas, interessado em microbiologia, dedicava-se a atividades no laboratório do avô, nos momentos de folga. Em 1896 foi a Paris especializar-se em microbiologia. Passou dois anos e meio no Instituto Pasteur. De volta ao Brasil, retomou as atividades clínicas e montou pequeno laboratório, até ser convidado a trabalhar no Instituto de Manguinhos, começando sua carreira de pesquisador. Com ele trabalhavam dois jovens estudantes de Medicina: Henrique Figueiredo Vasconcellos e Ezequiel Caetano Dias. 
Ezequiel Caetano Dias, concunhado de Oswaldo Cruz, no entanto, foi obrigado a se afastar de Manguinhos. Para tratar de uma tuberculose, deslocou-se para Belo Horizonte, cujo clima era considerado mais saudável e apropriado para o tratamento daquela doença. Aqui chegando, fundou uma filial de Manguinhos. Segundo Schwartzman (1979), "... a filial do instituto em Minas parece haver sido, sobretudo, uma forma de prolongarlhe a vida, sem interromper sua carreira de pesquisador" (p. 157).

Ezequiel Dias constitui, como já vimos, o grupo dos catedráticos fundadores da Faculdade de Medicina de Belo Horizonte. Ele não foi o único cientista do grupo de Manguinhos a procurar Belo Horizonte por motivo de saúde ${ }^{3}$. Também vieram Marques de Lisboa, Borges da Costa, Almeida Cunha e Hugo Werneck, todos catedráticos fundadores da escola de Medicina de Belo Horizonte. Como disse Martins (1990), "... o clima favorável à cura da tuberculose gerou um clima favorável ao florescimento científico em Minas Gerais" (p.56).

Além daqueles médicos, a nova faculdade contratou Carlos Pinheiro Chagas, primo do famoso cientista. Antes mesmo de começar a atuar como professor, Chagas ganhou bolsa da Fundação Rockfeller, para se especializar nos Estados Unidos. Ele foi o primeiro bolsista daquela fundação americana. Carlos Pinheiros Chagas não era o único parente do cientista, no corpo docente fundador da faculdade. O principal articulador do seu processo de criação e primeiro diretor da faculdade, Cícero Ferreira, era também parente de Carlos Chagas.

A filial de Manguinhos estimulava em Belo Horizonte o interesse pela pesquisa.

O Instituto Ezequiel Dias, além de seus trabalhos importantes no desenvolvimento e produção de soro antiofidico e antiescorpiônico, parece ter

\footnotetext{
${ }^{1}$ Por motivo de saúde vieram para Belo Horizonte, no início do século, os médicos professores da Faculdade de Medicina: Ezequiel Dias e Hugo Werneck (que fora contra a criação da faculdade), do grupo fundador. Roberto Almeida Cunha e Marques Lisboa, que se incorporaram, mais tarde, ao corpo docente, também se deslocaram para Belo Horizonte pelo mesmo motivo.
} 
sido o verdadeiro centro intelectual da vida acadêmica belo-horizontina. Seus pesquisadores mantinham contatos constantes com Manguinhos, para onde enviavam também as pessoas que iam se formando. Do grupo faziam parte Aroeira Neves, bacteriologist;) e micologista; Melo Campos, especialista em escorpiões e cobras; Otávio Magalhães, sucessor de Ezequiel Dias na direção do instituto; e o jovem Amílcar Vianna Martins, que entra para o instituto em 1924, com 17 anos (Schwartzman, 1979, p.58).

A biblioteca do Instituto Ezequiel Dias, segundo Schwartzman, assinava revistas internacionais e realizava "reuniões para a apresentação e discussão dos artigos principais, que atraíam professores da Faculdade de Medicina, não diretamente ligados ao instituto" (Schwartzman, 1979, p. 158).

No governo de Benedito Valadares, ao final da década de 30, o Instituto Ezequiel Dias entrou em decadência, enquanto centro de pesquisa e foi transformado em centro industrial de fabricação de soros. A tradição de pesquisa foi "mantida precariamente na Faculdade de Medicina até a criação do Instituto Nacional de Endemias Rurais" (Schwartzman, 1979, p. 159). A criação do Ineru (hoje René Rachou), em Minas, deve muito ao catedrático Amílcar Vianna Martins.

Além desses professores que se ligavam à pesquisa, a Faculdade de Medicina contou com um catedrático que era pesquisador em Manguinhos, no Rio de Janeiro. Trata-se de Eurico Azeredo Vilela, titular da cadeira de Patologia Geral. Passava temporada curta em Belo Horizonte, durante o início do ano letivo, retornando depois ao Rio e deixando em seu lugar um assistente (Nava, 1985).

A articulação da faculdade com o mundo científico também se expressou nas trajetórias de dois dos mais importantes catedráticos da área, já citados no trabalho. José Baeta Vianna, o mutante, que criou linha de pesquisa na química fisiológica. Foi reitor da Universidade do Distrito Federal (UDF), criada em 1935, sucedendo a Afonso Pena Jr. A UDF contava com uma Escola de Ciência que visava à formação de professores do curso secundário e pesquisadores. Baeta Neves foi um dos primeiros brasileiros a passar temporada nos Estados Unidos com bolsa da Rockfeller 
(Schwartzman, 1979). Amílcar Vianna Martins, por sua vez, dirigiu o Instituto Oswaldo cruz durante o governo Juscelino Kubistcheck.

Essa proximidade da Faculdade de Medicina com as instituições de pesquisa, no início, não alterou significativamente o currículo do curso de Medicina. Esses professores-pesquisadores dividiam suas atividades - ensino na faculdade e pesquisa na instituição própria para esse fim. Com certeza, o ensino que proporcionavam aos alunos do curso de Medicina era marcado pela sua experiência fora da universidade. E, como já vimos, alguns deles contribuíram para a implantação da mentalidade científica na formação dos médicos. Mas, no início, a verdadeira atividade de pesquisa desses docentes acontecia fora da universidade. Wilson Beraldo (1990) não se lembra da existência dessa função na Faculdade de Medicina, enquanto aluno. Não existia, segundo ele, pesquisa em fisiologia nem em bioquímica. Segundo ele, o professor Amílcar Vianna Martins fazia alguma coisa na Parasitologia, mas o seu verdadeiro laboratório se encontrava na Fundação Ezequiel Dias. Ali também outro professor, Octávio Magalhães, pesquisava o escorpião.

$\mathrm{Na}$ verdade o curso de Medicina de Belo Horizonte, apesar desses laços, seguia a orientação clínica da Faculdade do Rio de Janeiro. Provavelmente, essa proximidade com o campo da ciência, tornou a faculdade mineira mais sensível e receptiva ao modelo de medicina científica. Isso explica o empenho do catedrático Baeta Vianna, já assinalado anteriormente. Não sendo um pesquisador, contribuiu para a emergência de condições que propiciaram a adoção do novo modelo de medicina e de formação dos médicos. Como já foi dito, essa mudança na orientação das atividades profissionais do médico deu ensejo à emergência da pesquisa. Somado a isso, outros fatores contribuíram para que tomasse corpo, na Faculdade de Medicina, essa prática. Foi fundamental a participação da Fundação Rockfeller. Através de seu apoio financeiro, foi possível, por exemplo, a instituição do tempo integral para alguns professores e a instalação de laboratórios já nos anos 60. Assim, algumas 
cadeiras básicas do curso de Medicina conseguiram construir infraestrutura necessária ao desenvolvimento de atividades de pesquisa.

Não era apenas na Faculdade de Medicina que o ensino e a pesquisa da Biologia aconteciam ou começavam a acontecer. Nas demais faculdades da saúde (Odontologia, Farmácia, Veterinária), cadeiras básicas do campo da Biologia também existiam.

Enquanto na Odontologia, Farmácia e Veterinária a pesquisa ocupava no currículo e no espaço institucional lugar secundário, de apoio às cadeiras de formação profissional, na Faculdade de Filosofia (Fafí) sua situação era diferente.

Criada em 1939 como instituição privada, rejeitada pela universidade, a Faculdade de Filosofia, como as outras em geral, foi produto de uma perspectiva diferente daquela que orientara a criação das universidades. Tinha como fundamento a negação da universidade. Era um agregado de escolas profissionais existente. Deveria se constituir em centro de altos estudos, reflexão filosófica, cultivo da ciência e das letras clássicas, ou seja, do saber autônomo, desvinculado da formação profissional. Sua incorporação à universidade se deu em 1948, pressionada pela legislação que previa que as universidades teriam de contar com uma Faculdade de Filosofia. Apesar desse suporte legal, a luta por sua incorporação durou seis anos, "... seis anos de silenciosa luta" (Haddad, 1988, p.106). Nessa luta, já estavam em confronto propostas diferentes de universidade.

Se a perspectiva acadêmica dos fundadores da Faculdade de Filosofia representava vertente progressista, em nível político, eles se associavam ao fascismo. Recusada pela universidade, a Faculdade de Filosofia nasceu sob a proteção da Casa d'Italia. Seu primeiro diretor. Lúcio José dos Santos, de direita, era ligado aos líderes católicos mineiros e a essa instituição italiana, que desenvolvia atividades culturais, relacionadas com o projeto de Mussolini de expansão do fascismo. Instalada no prédio pertencente àquela Casa, a Fafi encontrou, por esse motivo, dificuldades no processo de autorização 
dos cursos, pelo Conselho Nacional de Educação. As relações com a Casa d'Italia foram intensas até 1942.

Progressista academicamente e conservadora do ponto de vista político mais amplo, assim foi a Faculdade de Filosofia em suas origens. Em seus primeiros anos, não foi fácil desenvolver ali o exercício da pesquisa. Instalada em prédio emprestado até 1952, sem equipamentos adequados, encontrava dificuldades para estimular essa atividade e a formação de pesquisadores. Alguns professores, interessados nessa área, utilizavam laboratórios das faculdades profissionais, como Medicina, Engenharia e Farmácia.

Num dos departamentos da Fafi, a biologia podia ser ensinada e pesquisada de forma autônoma, sem as relações de dependência que conhecia na Faculdade de Medicina e nas demais unidades. Era o Departamento de História Natural. Foi o primeiro a se equipar, tendo em vista a pesquisa, sob os auspícios do catedrático Braz Pellegrino.

O Departamento de História Natural contava com três cadeiras biológicas e três não-biológicas. As primeiras eram dirigidas por professores do corpo docente da Faculdade de Medicina: Biologia Geral - Braz Pellegrino; Zoologia - Amílcar Vianna Martins e Waldemar Versiani e um professor da Farmácia; Botânica - Lair Remussa Rennó.

Em 1948, o departamento, através do esforço de Braz Pellegrino, contratou um cientista italiano que estava em São Paulo, Giorgio Schreiber ${ }^{4}$. Biólogo de formação, já era pesquisador na Itália quando foi demitido no âmbito das perseguições fascistas. Veio para São Paulo em 1940, onde trabalhou como químico em empresa e, precariamente, como pesquisador,

\footnotetext{
${ }^{4}$ O professor Giorgio Schreiber, doutor em Zoologia e Anatomia Comparada, nasceu em Trieste e estudou na Universidade de Pádua, onde lecionou e pesquisou. Junto com sua mulher, imigrou para o Brasil, fugindo do clima anti-semita europeu, em 1940. Trabalhou como laboratorista em São Paulo, antes de retomar as atividades de pesquisa. Em 1944, foi contratado pelo Instituto Butantã onde ficou até 1948, quando então se deslocou para Belo Horizonte. Em 1949, tomou posse da 2* cadeira de Zoologia da Faculdade de Filosofia. Co-fundador da SBPC e da Sociedade Brasileira de Genética, Schreiber era membro titular da Academia Brasileira de Ciências, da Academia de Ciências de Nova York e da Sociedade Internacional de Biologia Celular. Sua trajetória era já a de um pesquisador (Carvalho, 1975).
} 
apoiado pelo Departamento de Zoologia da Faculdade de Filosofia, Ciências e Letras da USP e da Seção de Citogenètica do Instituto Butantã.

Convidado a compor a equipe do Departamento de História Natural da Faculdade de Filosofia de Belo Horizonte, Schreiber impôs, para aceitar o convite, algumas condições: contrato em tempo integral, sala para realizar seus trabalhos, assistente em tempo integral, aquisição de uma lista de livros, assinatura de revistas e uma cátedra. Com ele chegou o primeiro microscópio. Tendo sido formado na prática de pesquisa, Schreiber foi o primeiro grande formador de novos pesquisadores. Seu método de trabalho influenciou a prática pedagógica do departamento.

Schereiber participava e estimulava seus alunos a acompanhar, através dos periódicos especializados, a produção científica no país e no mundo, a freqüentar reuniões científicas, a se empenhar em atividades de pesquisa.

Para reforçar a pesquisa, o departamento criou o Instituto de Biologia Geral, a partir da associação da cátedra de Schreiber (Zoologia dos Vertebrados) e de Braz Pellegrino (Biologia Geral) ${ }^{5}$. A criação desse instituto estava prevista no primeiro regimento da Faculdade de Filosofia.

Apesar da cátedra destinada a Schreiber ter sido a de Zoologia dos Vertebrados, sua atuação e sua competência científica faziam-no, no entanto, o grande biólogo do departamento interessado em pesquisa básica. Braz Pellegrino, o catedrático de Biologia, não foi exatamente um pesquisador. Como outros catedráticos da universidade, àquela época, ele pode ser também identificado como mutante, estimulando a implantação da pesquisa sem, no entanto, ter desenvolvido essa prática, tal como Baeta Viana, da Medicina, e Francisco Magalhães, da Engenharia.

Assim, a pesquisa de Biologia na Fafi foi gerada pela associação de dois homens que, politicamente, estavam em campos opostos, mas que,

\footnotetext{
${ }^{5}$ A trajetória do professor Braz Pellegrino, já esboçada no corpo deste capitulo, mostra que a Faculdade de Medicina não o acolheu e faz pensar no que Bourdieu disse a propósito da origem da pesquisa nas Ciências Sociais na França: "(...) a pesquisa foi, no começo, com freqüência, uma forma de escapar ou um refúgio para os excluídos das carreiras tradicionais" (Bourdieu, 1984, p. 161).
} 
academicamente, estavam comprometidos com a criação de uma universidade moderna. Braz Pellegrino, italiano, amigo da fascista Casa d'Italia, e o judeu Schreiber, que viera para o Brasil fugindo daquele regime.

O primeiro assistente de Schreiber, contratado em tempo integral, de acordo com suas demandas, foi o filho de Braz Pellegrino, José Pellegrino, formado em Medicina. Sob a orientação de Schreiber, José Pellegrino, tornou-se pesquisador reconhecido por seus trabalhos sobre esquistossomose e contribuiu para alimentar a formação científica dos alunos do curso de História Natural. Criou o Grupo Interdisciplinar de Esquistossomose (Gide), que produziu um número significativo de trabalhos. Apesar de não ter sido um grande mestre, José Pellegrino teve importância na formação de uma geração de pesquisadores.

As atividades de pesquisas de Schreiber e José Pellegrino, principalmente nos primeiros tempos, foram desenvolvidas nos laboratórios do Ineru. Aos poucos, foram sendo construídas as condições para a realização de pesquisa no próprio departamento.

A situação dos catedráticos do Departamento de História Natural, na estrutura acadêmica de poder, era diferente daqueles da área básica da Faculdade de Medicina. No âmbito da Faculdade de Filosofia, os catedráticos pesquisadores ocupavam lugar de prestígio. Ali a formação profissional não era dominante. Primeiramente, porque o espírito que alimentara a própria criação da faculdade supunha uma interpretação diferente de universidade. Era mais moderna. Em segundo lugar, a profissão de professor não era socialmente prestigiada. Se internamente o lugar da pesquisa era mais confortável, no confronto com as faculdades de prestígio, no âmbito da universidade, a Faculdade de Filosofia era desprestigiada.

Assim, nos anos 60, a pesquisa e o ensino da Biologia ocupavam posições dominadas. Dominada no interior da Faculdade de Medicina, faculdade de prestígio. Dominante na Faculdade de Filosofia, faculdade de pouco prestígio. Essas posições no campo da força simbólica da universidade contribuíram para a compreensão do envolvimento desses atores no momento da reforma e da luta e, em particular, para a implantação do Instituto Central de Biologia. Os catedráticos da área básica da Faculdade 
de Medicina empenharam-se por essa mudança. Apesar da adesão ao projeto, os professores do Departamento de História Natural receavam ser engolidos pelos colegas da Medicina no novo espaço de trabalho.

\section{Tensões acadêmicas e a implantação do ICB}

Nos anos 60, a UFMG já contava com um corpo de pesquisadores em biologia. Alguns deles tinham competência reconhecida nacionalmente. Mas o crescimento dessa atividade era constrangida pelo modelo de universidade existente. A estrutura universitária, produzida pelo agregado de faculdades e articulada em torno da cátedra, privilegiava a formação profissional. Nessa estrutura, a pesquisa e seus agentes ocupavam lugar secundário. Assim, compreende-se que essa categoria docente almejasse uma reorganização da universidade que lhes fosse mais favorável.

No nível universitário, essa reestruturação encontrava adesões e oposições claramente definidas. Na Faculdade de Medicina da UFMG, como se pode depreender por este estudo, articulam-se a favor da implantação do Instituto Central de Biologia catedráticos da área básica. Neste instituto, a pesquisa biológica seria prioritária e a Biologia, enquanto disciplina autônoma, encontraria condições de se afirmar. Por isso, foi em torno dele que se concentrou a disputa propriamente acadêmica.

Do ponto de vista dos principais atores responsáveis pela reforma na UFMG, em sua etapa consentida, os interesses acadêmicos em jogo pareciam claros. Tratava-se de dar nova organização à universidade, transformando-a numa instituição produtora do saber, nos moldes das universidades modernas. Isso supunha o enfrentamento dos interesses das faculdades profissionais de prestígio que dominavam a universidade. Por isso, era natural que a maior resistência ao projeto de reestruturação da universidade se localizasse, como disseram Veiga et alii (1987), entre

(...) ferrenhos defensores da continuidade da cátedra e da completa autonomia, até então gozada pelas escolas profissionais. Os principais focos de resistência 
à reforma e, conseqüentemente, à criação dos institutos centrais localizaramse nas Escolas de Medicina, Engenharia, Arquitetura e Direito (p.27).

Um dos núcleos da reorganização da universidade proposta pelo reitor Aluísio Pimenta (1964-1967) constituía-se na criação de institutos centrais. Neles, as atividades de pesquisa seriam privilegiadas:

Pensava-se a universidade como tendo duas pulsações básicas: 1) a pulsação interna, para dentro da própria universidade, que seria produzida pelos institutos centrais, mais vinculados ao ensino daquilo que a universidade concebia como básico e, ao mesmo tempo, produzindo conhecimento sobre aquilo que a comunidade de pesquisadores julgasse relevante; 2) a pulsação externa, mais voltada para os interesses da comunidade (Veiga et alii, 1987, p.24).

Os estatutos da universidade, ajustados às exigências da LDBEN (1961), previam a criação dos institutos de Matemática, Física, Química, Ciências Biológicas, Ciências Geológicas, Direito Público e Ciências Políticas. Neles se ensinariam as disciplinas consideradas básicas dos cursos de graduação das escolas profissionais e dos próprios institutos, e se implementaria o ensino de pós-graduação, articulado com as atividades de pesquisa. Nos institutos centrais, as disciplinas encontrariam suporte institucional para sua expansão; as atividades de pesquisa e de formação dos novos pesquisadores (pós-graduação) seriam prioritárias. Dada a posição dos institutos, na estrutura organizacional da nova universidade, o que se propunha era uma reinversão dos valores que hierarquizavam o campo acadêmico.

No projeto original de reforma da UFMG, os institutos seriam localizados no campus, "mais protegido do ambiente externo", deixando as escolas profissionais "dispersas no tecido urbano". Como suporte à pesquisa, propunha-se a criação do Conselho de Pesquisa, de bibliotecas centrais por área, e a implementação do regime de trabalho em dedicação exclusiva para os professores.

Por tudo isso, e tendo em vista a história específica, aqui relatada, da Faculdade de Medicina, entende-se que, em termos organizacionais, eram os institutos centrais a aposta principal do grupo que defendia a 
reforma. E entende-se, também, porque as oposições à reorganização aí emergiram com força.

No caso do Instituto Central de Biologia, a oposição parece ter sido mais virulenta que nas demais. E o que se conclui pela leitura do estudo de Veiga et alii (1987). A estratégia que o grupo do reitor Aluísio Pimenta formulou para iniciar a implantação das reformulações, partindo da avaliação da composição de forças na universidade, previa resistência particular da Faculdade de Medicina:

A forna proposta para a implantação do Instituto Central de Ciências Biológicas (ICB) demonstra a cuidadosa estratégia posta em prática por Aluísio Pimenta e sua equipe, com o intuito de superar as resistências ao plano de reforma. A opção pela gradualidade, envolvendo primeiro aquelas unidades que, como a Fafi e também a Faculdade de Farmácia, abrigavam grande número de aliados da reitoria, visava, certamente, acumular forças para o enfrentamento posterior das unidades mais resistentes à reforma, como era o caso da Medicina. De fato, a incorporação do setor de biologia aplicada ao ICB implicava grande resistência por parte desta Faculdade, pois com esse setor viriam exatamente aqueles pesquisadores de mais prestígio acadêmico e, conseqüentemente, os equipamentos e recursos financeiros que viabilizavam seus trabalhos. Mas é necessário ressaltar, também, que tais pesquisadores ligados às áreas básicas eram os mais identificados coin as mudanças propostas e nessa medida aliados do reitor (Veiga et alii, 1987, p.26).

A resistência particular da Faculdade de Medicina, identificada por Veiga, e que a diferencia, inclusive, das faculdades profissionais de prestígio, que também viam sua posição de dominação acadêmica ameaçada pela criação dos institutos centrais, explica-se, entre outros motivos, pela importância especial que as disciplinas básicas desempenhavam no currículo de formação dos médicos. Talvez mais que nas outras faculdades de prestígio, o deslocamento daquelas disciplinas traria desdobramentos acadêmicos mais profundos.

A evolução que tomara o próprio ensino médico, com a adesão ao modelo americano da Medicina dita "científica", e o deslocamento das cadeiras básicas, da pesquisa, dos pesquisadores e dos laboratórios para o ICB significavam um evidente empobrecimento para o conteúdo e a 
prática pedagógica das cadeiras profissionais. Alguns catedráticos entrevistados se referiram a isso como "perda de substrato científico". Com o ICB, as cadeiras clínicas perderiam "a cozinha" da pesquisa.

Se era vital para os catedráticos manter a área básica na Faculdade de Medicina, ocupando lugar secundário no currículo e na instituição, a importância e a força do trabalho que vinha sendo realizado por esses professores, reconhecido no emergente campo da Biologia, faziam do espaço daquela unidade um campo de batalha. As posições eram claras. A favor da criação da ICB, uniam-se, em geral, os catedráticos da área básica. Contra essa criação, argumentavam e movimentavam-se os docentes da área profissionai.

Antes mesmo da administração de Aluísio Pimenta, os catedráticos da área básica, apoiando-se nos dispositivos estatutários da universidade, endereçaram à Reitoria documento, solicitando a criação do ICB. Isso não foi atendido.

O peso dos interesses em conflito na Faculdade de Medicina contribuiu para dificultar a criação daquele instituto central. Durante esse processo, coordenado pelo reitor Aluísio Pimenta, não foi possível criar o ICB. Este só se concretizou após a lei que tornava obrigatória a implantação da reforma. Mesmo nesse período, não foi tranqüila a reorganização decorrente da criação do ICB. Os professores do recém-criado instituto, que possuía instalações no prédio da Faculdade de Medicina, tiveram, em alguns casos, que usar de força para poder ocupar as salas que lhes tinham sido designadas.

Assim, os atores que lutavam na UFMG, para a implantação de um projeto modernizante de universidade, só puderam conseguir seus objetivos com o apoio legal do governo central.

\section{A reforma e seus efeitos perversos}

A reforma da universidade, que contemplava uma estrutura mais adequada ao desenvolvimento da pesquisa, como todos sabemos, foi implantada. 
A estrutura atual, com os institutos centrais, com órgãos centrais de coordenação da pesquisa e da pós-graduação (nível por excelência de formação de pesquisadores), efetuou uma alteração nas legitimidades acadêmicas.

Como se sentem hoje os protagonistas dos conflitos aqui analisados? A leitura de depoimentos de ex-catedráticos da Faculdade de Medicina e da pesquisa emergente no periodo da pré-reforma fornecem informações interessantes ${ }^{6}$.

Alguns trechos serão apresentados em dois blocos. No primeiro, trechos das entrevistas de ex-catedráticos da área básica, incluindo alguns da Faculdade de Medicina e Odontologia; no segundo, trechos das entrevistas realizadas com ex-catedráticos da área profissional da Faculdade de Medicina.

\section{EX-CATEDRÁTICOS DA ÁREA BÁSICA}

Na época da cátedra, o catedrático era o responsável pelo ensino de graduação. Nós, catedráticos, dávamos aula efetivamente o ano todo; nem passava pela cabeça de um professor assistente dar aulas teóricas. As aulas teóricas eram propriedade dos professores catedráticos. As aulas teóricas eram dadas durante o ano inteiro; os catedráticos davam o programa. Aí já está uma coisa interessante, pelo menos aqui na nossa área; é difícil uma pessoa dar um programa. Em geral, as pessoas vão lá, dão uma aula e pronto. Na época da cátedra, definia-se o número de aulas, o número de alunos, a metodologia, as provas. O seu poder (catedrático) na área de ensino era mais (...)

— Eu acho que hoje cm dia o que há é um descompromisso total. O que você vê é gente preocupada com seu laboratório, com sua pesquisa, mas o nível de compromisso institucionalizado é muito pequeno (...) Eu acho que a universidade está ficando descerebrada

- (...) As pessoas chegam ao Conselho Universitário sem saber o que aconteceu na universidade (...) O sujeito é professor, sem maiores participações, é lançado

'Para o presente trabalho, foram entrevistados cinco ex-alunos de catedraticos, quatro ex-catedráticos da área básica, os quais tiveram papel importante de apoio e sustentação à criação do ICB, e três ex-catedráticos da área profissional. 
para membro do Conselho Universitario. Antigamente, o sujeito para chegar à cátedra com menos de 40, 50 anos, não chegava. Ele tinha um percurso, um compromisso estatutário, tinha uma vida institucional muito grande (...) Ninguém chegava a diretor de escola facilmente

- (...) Eu acho que para chegar a diretor ou reitor tem que ter carreira carreira acadêmica. Há uma hierarquia da competência, do saber, que na universidade não pode ser dissociada. A cátedra, parece, compatibilizava isso. A cátedra foi evidenciada na luta pela reforma. Foi a grande alavanca. Ela ficou sendo vista como uma coisa negativa, mas ninguém a analisou. $\mathrm{Eu}$, por exemplo, era professor catedrático e fui contra a cátedra. Mas se arrependimento matasse! (...)

- Os departamentos (da UFMG) fortes foram construídos a partir das cátedras. Porque você tem um bom departamento de Bioquímica devido ao catedrático chamado Baeta Viana. O mesmo ocorre com o Departamento de Parasitologia. Lá você tem a presença do professor Amilcar Viana. São pessoas competentes e que tinham competência para articular em torno delas pessoas competentes (...) Eu acho que a cátedra migrou da graduação para a pósgraduação (...) A extinção da cátedra para a graduação, em qualquer lugar, foi péssimo (...) Baixou a qualidade do docente na graduação. Pelo menos o catedrático tinha passado por concurso e, ao assumir, dominava o conteúdo.

\section{EX-CATEDRÁTICOS DA ÁREA PROFISSIONAL}

-... Sea cátedra funcionava bem, o crédito era do catedrático; se a cátedra não funcionava bem, o crédito era também do catedrático. Então dependia do catedrático. Quer dizer, era possível identificar e responsabilizar diretamente aquele professor que não era assíduo, que não levava o trabalho a sério, que não submetia os alunos à rigidez de exames periódicos, que aprovava todos os alunos. $\mathrm{O}$ bom catedrático era aquele que ensinava e cobrava, que reprovava quem não sabia.

Foi um erro a criação dos institutos, porque o ideal, para uma Faculdade de Medicina, seria que as cadeiras básicas estivessem juntas 
com as cadeiras do ensino profissionai, que pudesse haver o intercambio que havia. Então, o que a escola já tinha desenvolvido... já tinha um prédio com as cadeiras básicas bem instaladas, os hospitais estavam todos aqui. Pode ser que para outras universidades brasileiras pudesse ter sido bom, mas para Minas nao foi, porque tirou as cadeiras e levou-as para a Pampulha; no lugar das cadeiras básicas não ficou nada; elas podem até estar bem instaladas lá e nem queiram voltar. A escola ficou só com o ensino profissionai. A pesquisa não pode ser desligada do ensino; não pode haver só pesquisa pura (...) A vantagem principal da cátedra (...) uma liberdade total para dar a disciplina (...) poderia criar uma linha de pesquisa, uma linha de ensino, uma escola, afinal. O que hoje, me parece, não existe; é muito colegiado; não há uma responsabilidade única... é mais grupo, colegiado. Há muita reunião. Se se quiser saber qual a linha do professor, você não sabe (...) A primeira greve que houve foi para acabar com a vitaliciedade da cátedra. Poderiam ter feito alguma coisa nesse sentido, em vez de acabar com a cátedra (...) hoje todo mundo é vitalício (...) ninguém é demitido, por coisa nenhuma (...) É vitalício na prática (...). O Departamento, como existe, atualmente, é apenas administrativo. Não existe uma linha de pesquisa, de ensino.

- A cátedra é uma instituição que não deveria ser destruída (...). Um dos diretores de um setor ativista contra cátedra me pediu para tomar conta do setor. Ele me disse que havia se arrependido, porque nesse setor, apesar de serem seis pessoas, só dois professores comparecem (...). Nós éramos professores de alto nível universitário. Realmente, o que se exigia para se chegar a catedrático era uma responsabilidade enorme (...). Acho perfeitamente exeqüível (a volta da cátedra). Acho que deveria colocar o catedrático responsável por aquele setor; responsável perante a congregação e perante a lei do país. Sem essa responsabilidade, não tem jeito; todo mundo manda, todo mundo dá palpite, para tudo se precisa de assembléia. O que está acontecendo na escola é um pedacinho do que está acontecendo no Brasil. Nós estamos desordenados.

Os ex-catedráticos da área profissional manifestaram-se a favor da cátedra como núcleo da organização da universidade. Apontaram vantagens tais como: definição clara das responsabilidades na definição 
de programas, cursos etc.; qualificação dos professores (catedráticos) e dos administradores da universidade; a possibilidade de estruturação de grupos de ensino-pesquisa em áreas do conhecimento necessárias à formação do médico; articulação do ensino em níveis de graduação e pesquisa. Para alguns deles, a universidade atual estendeu a todos os professores a vitaliciedade do cargo, sem exigir o mesmo nível de qualificação acadêmica. Nesse sentido, todos os professores atuais são vitalícios sem terem que percorrer a trajetória acadêmica do catedrático. Criticam, também, a desvinculação entre carreira e acesso a cargos da administração universitária.

Entre os ex-catedráticos da área básica podem ser encontradas críticas à cátedra e críticas à universidade pós-reforma.

Apesar de terem lutado pela implantação da reforma e, em particular, evidentemente, pela criação do Instituto Central de Biologia, eles apontam problemas na estrutura atual. Alguns chegaram mesmo a falar em "arrependimento" do esforço realizado para implantar a reforma e apontam aspectos positivos da cátedra. Outros, que mantêm integral rejeição à cátedra, falam dos efeitos perversos e das distorções que emergiam no processo de implantação da reforma. Em suas críticas a essa universidade que ajudaram a construir, ex-catedráticos da área básica apresentam argumentos que podem ser reunidos em duas categorias. A primeira ordem de argumentos referese às conseqüências ou aos desdobramentos inerentes à própria proposta de universidade moderna. A reforma proposta tinha como núcleo de mudança a busca de uma estrutura organizacional que privilegiasse a atividade de pesquisa. Isso supunha a criação de mecanismos de apoio à pesquisa (Conselho de Pesquisa, Institutos Centrais) e o estímulo ao ensino na pósgraduação, onde se formam os agentes da pesquisa. A grosso modo, podese falar em uma certa identidade entre ensino de pós-graduação e atividade de pesquisa.

A busca de redirecionamento dos objetivos da universidade, tendo em vista sua modernização, supunha, primordialmente, o estímulo à 
pesquisa, à produção de conhecimento e à formação de pesquisadores. A identidade social do pesquisador constrói-se num espaço simbólico diferente da identidade do professor não-pesquisador. Para a construção de sua identidade profissional, o pesquisador orienta-se por balizas fornecidas pelo campo mais amplo de sua disciplina, no caso, a Biologia. São importantes nesse processo os congressos científicos, as publicações em revistas especializadas, as associações, as instituições de financiamento à pesquisa em níveis nacional e internacional. Isso tudo remete o professorpesquisador a um espaço que ultrapassa o da instituição onde atua.

Algumas das críticas de ex-catedráticos da área básica referem-se às conseqüências "naturais" do modelo de universidade que investe em pesquisa.

A segunda categoria de argumentos utilizados por ex-catedráticos da área básica, contra a universidade atual, aponta para o que chamam de deformações na implantação da reforma. Nesse sentido, suas críticas se aproximam daquelas elaboradas pelos ex-catedráticos da área profissional. Falam em perda de consistência dos valores acadêmicos e criticam a estrutura, que permite a baixa qualificação acadêmica de muitos professores que ocupam postos de direção.

Essas críticas induzem a uma hipótese cuja comprovação exigiria um estudo sobre o campo acadêmico atual, seus valores, seus conflitos e, principalmente, sua estrutura de poder. Priorizando, como foi feito nesta análise, a dimensão acadêmica dos conflitos, o arrependimento dos excatedráticos da área básica pode ser interpretado como avaliação de que os frutos de sua luta não corresponderam aos objetivos perseguidos. Tratava-se de dar à pesquisa e aos agentes dessa prática um lugar hegemônico na estrutura universitária.

No entanto, articulada aos conflitos políticos mais amplos, a estrutura de poder que emergiu, privilegiando formas mais democráticas de acesso aos cargos de direção, levou ao que eles chamam de "efeitos perversos", ou seja, à minimização dos valores propriamente acadêmicos 
na academia. O conflito pré-reforma opunha interesses acadêmicos diferentes. A estrutura que emergiu daí não correspondeu aos anseios de seus defensores, na medida em que possibilitou o exercício do poder por professores cujas trajetórias não eram orientadas pelo investimento acadêmico. Assim, a universidade nova redefiniu suas hierarquias de poder numa direção cujos resultados se distanciam da universidade pretendida pelos atores que por ela lutaram.

Na luta contra a oligarquia dos catedráticos, teria sido criada uma outra oligarquia que hoje controla a universidade, "muito mais complexa e opaca, muito mais dificil de ser apreendida e combatida (Veiga, 1987, p.35).

Essa crítica dos ex-catedráticos entrevistados explicita conflitos atuais do campo acadêmico e que ainda não foram devidamente analisados.

\section{Observações finais}

A tensão ocorrida na Faculdade de Medicina, que se articulou, como vimos, à emergência e à institucionalização da Biologia como disciplina acadêmica, tem sido uma invariante na história das universidades. Esse tipo de tensão foi mais agudo nos países que conheceram mais tardiamente o desenvolvimento científico e que importaram, de outras partes, a prática de pesquisa (Gingras, 1991a).

No estudo das origens da pesquisa no campo da Física, no Canadá, Gingras (1991, a e b) aponta as linhas gerais da história de uma disciplina científica. Numa primeira etapa, emergem as condições que propiciam a prática de pesquisa no campo científico. Os primeiros pesquisadores universitários procuram impor uma concepção de universidade que possibilite colocar sua prática em posição dominante e que permita a reprodução, a longo prazo, do seu grupo. Essa primeira fase, de conquista institucional, exige, quase sempre, luta. Em primeiro lugar, pela sobrevivência dos pesquisadores e, em seguida, pelo crescimento da 
comunidade científica. Isto supõe a imposição de "... uma concepção de instituição universitária compatível com suas atividades científicas e que permita a reprodução a longo prazo do grupo" (Gingras, 1991a, p. 13).

Essa institucionalização constitui uma fase crucial na organização da comunidade científica.

$\mathrm{Na}$ falta de estruturas institucionais que favoreçam a produção de conhecimento e a reprodução dos agentes capazes de assegurar esta produção, é ilusório acreditar que os cientistas possam participar das atividades constitutivas de um campo científico enquanto tal (Gingras, 1991a, p. 13).

Finalmente, conquistada a reforma institucional, os pesquisadores de um campo científico procuram constituir sua identidade social, através de organizações científicas ou profissionais. Adquirem, então, visibilidade social, divulgam uma imagem de sua categoria, de sua atuação, e defendem seus interesses, enquanto grupo social, e os interesses de sua disciplina científica.

A reconstrução de fatos relativos à história da Faculdade de Medicina aponta para a pertinência da análise de Gingras. Os conflitos acadêmicos assinalados articulam-se à emergência, à institucionalização e à construção da identidade social dos biólogos. A alteração do modelo de medicina constitui, entre outros fatores, condição para a emergência da pesquisa biológica. A luta pela implantação do ICB, no contexto da reforma da universidade, vitoriosa, possibilitou a alteração da instituição adequada aos interesses dos biólogos. Como os biólogos pesquisadores de outros campos científicos, também procuravam construir melhores condições institucionais para suas atividades e seus interesses.

A reforma universitária dos anos 60 , como se sabe, atende a esses interesses que se somavam a demandas de outros setores sociais. O modelo organizacional implantado - com o ciclo básico, os institutos centrais, os conselhos de pós-graduação e pesquisa — deu à prática de pesquisa novo estatuto. 
A prática de pesquisa tornou-se, então, dominante no seio da universidade? As opiniões dos ex-catedráticos levantam questões interessantes que não permitem uma resposta imediata a essa questão. Essa avaliação demanda um estudo que considere as atuais relações de força simbólica no campo acadêmico.

\section{Referências bibliográficas}

BERALDO, Wilson. Paixão pelo laboratório. Ciência Hoje. São Paulo, v.12, n.67, p.48-56, 1990.

BLODIN. Denis. Les rapports entre l'enseignement et la recherche dans la profession d'universitaire. Montreal: Universidade de Montreal, 1987. Tese (Doutorado)

BOURDIEU, Pierre. Homo academicus. Paris: Ed. de Minuit, 1984.

La noblesse d'État: grandes écoles et esprit de corps.

Paris: Ed. de Minuit, 1989.

Système d'enseignement et système de pensée. Revue

Internationale de Sciences Sociales. Paris, n. 19, p.367-388, 1967.

La spécificité du champ scientifique et les conditions

sociales du progrès de la raison. Sociologie et Sociétés, Montreal, v.7, n.1,p.91-118, 1975.

Le sens pratique. Paris: Ed. de Minuit 1980.

BROWN, E.R. La santé publique et l'impérialisme: les premiers programmes Rockefeller aux Etats-Unis et dans le monde. In: BOZZINI, L. et al. (Org.). Medicine et Société — les armés 80. Québec: Ed. Coopératives Albert Saint Martin, 1981. 
BROWN, E.R.. Rockefeller medicine men: medicine and capitalism in America. Berkekey: University of California Press, 1979.

CAMPOS, Mário M. Cinqüentenário da Faculdade de Medicina da Universidade de Minas Gerais: notas, informações, comentários. Belo Horizonte: Imprensa Universitária de Minas Gerais, 1961.

CARVALHO, H.C. Professor Giorgio Schreiber - 50 anos de atividades de ensino e pesquisa. Ciência e Cultura, São Paulo, v.27, n.2, p. 121124, 1975.

ICB uma experiência de ciclo básico. In: ATAS ào Primeiro Simpósio sul Americano de Genética. [S.1.: s.n.]. 1961. p.80-93.

CARVALHO, M.C. da S. Medicina e ensino médico: vertentes de um processo de desenvolvimento econômico e social - uma história da Faculdade de Medicina de Belo Horizonte. Belo Horizonte, 1987. Dissertação (Mestrado) — UFMG.

DANDURAND, P. Accélération des mouvements de professionnalisation et de normalisation de la tache chez les universitaires québécois francophones, 1976-1990. In: LESSARD, C, PERRON,M., BELANGER, P.W. (Org). La profession enseignante au Québec. Québec: Institut Québécois de Recherche sur la Culture. 1991. p. 135-157.

Essai sur l'éducation et le pouvoir. Sociologie et Société. Montreal, v.3, n.2, p.209-227, 1971.

Un corp professorale renouvelé: les professeurs des universités québécoises francophones entre 1959 et 1976. Revue Canadiennne de l'Enseignement Supérieur, v. 19, n.1, p.63-85, 1989.

DANDURAND, P., OLLIVIER, E. Cenntralité des savoirs et éducation: vers de nouvelles problématiques. Sociologie et Sociétés. Montreal. V.23, n.1,p.2-23, 1991. 
DUCHESNE, Raymond. D'intérêt public et d'intérêt privé: l'institutionnalisation de l'enseignement et de la recherche scientifique au Québec, 1920-1940. In: L'AMONDE, Y, TREPANIER, E. (Org). L'avènement de la modernité culturelle au Québec. Québec: Institut Québécois de Recherche sur la Culture. 1986. p. 189-230.

FOURNIER, M., GINGRAS, Y, MATHURIN. L'évaluation par les pairs et la définition légitime de la recherche. Actes de la Recherche en Sciences Sociales. Paris, n.75, p.47-54, 1988.

GARDENAL, Lília, PAIXÃO, Antonio L. Ciclo básico na universidade brasileira: temas e problemas principais. Cadernos de Pesquisa, São Paulo, n.41,p.3-11, 1982.

GINGRAS, Y De l'enseignement à la recherche: l'émergence d'une nouvelle pratique de la physique dans les universités canadiennes. Histoire Social, Ottawa, v.19, n.37, p.73-91, 1986.

Le défi de l'université moderne: l'équilibre entre l'enseignement et la recherche. Possible, Montreal, v.ll, n.4, p. 151163, 1987.

. Les Origines de la recherche scientifique au Canada le cas des physiciens. Québec: Ed. du Boréal, 1991a.

L'institutionnalisation de la recherche en milieu universitaire et ses effets. Sociologie et Sociétés: Montreal, v.23, n.1, p.41-54, $1991 b$.

HADDAD, Maria de LA. Faculdade de Filosofia de Minas Gerais: raízes da idéia de universidade na UFMG. Belo Horizonte, 1988. Dissertação (Mestrado).

KARADY, V. Les professeurs de la république, le marché scolaire, les réformes universitaires et les transformations de la fonction 
professorale. Actes de la Recherche en Sciences Sociales, Paris, n.4748, p.90-112, 1983.

KOHLER, R.E. Science, foundations and American Universities in the 1920. In: OSIRIS. Pennsylvania: Departament of History and Sociology of Science, University of Pennsylvania, 1987. p. 135-164.

LE CLERC, M. La notion de discipline scientifique et ses enjeux. Politique. Montreal, n.15, p.23-51, 1989.

MAHEU, L. et al. La science au Québec francophone: aperçus sur son institutionnalisation et sur les conditions d'accès à sa pratique. Revue Canadienne de Sociologie et d'Anthropologie, Toronto, v.21, n.3, p.247-274, 1984.

MARTINS, Amílcar V. Zoólogo por natureza. Ciência Hoje, São Paulo. v.11,n.63, p.54-61, 1990.

MOURÃO, Paulo Kruger Correa. O ensino em Minas Gerais no tempo da República, 1889-1930. Belo Horizonte: Centro Regional de Pesquisas Educacionais de Minas Gerais, 1962.

NAVA, P. Beira Mar - memórias 4. 3 ed. Rio de Janeiro: Nova Fronteira, 1985.

SCHWARTZMAN, Simon. A árvore da ciência. Ciência Hoje, São Paulo. V.3, n.15, p.70-84, 1984.

Formação da comunidade científica no Brasil. São

Paulo: Nacional, 1979.

STEPAN, Nancy. Gênese e evolução da ciência brasileira. Rio de Janeiro: Artenova, 1976. 
VEIGA, L. et al. UFMG: trajetória de um projeto modernizante, 19641974. Revista do Departamento de História, Belo Horizonte, n.5, p.5-40, dez. 1987.

WIRTH, J.D. Minas Gerais na Federação Brasileira 1889-1937: o fiel da balança. Rio de Janeiro: Paz e Terra, 1982.

Recebido em 29 de novembro de 1995.

Léa Pinheiro Paixão, doutora em Ciências da Educação pela Universidade de Paris V, é professora titular de Sociologia da Educação do Departamento de Fundamentos Pedagógicos da Universidade Federal Fluminense (UFF).

This article presents outcomes of an empirical study. Starting from the analysis of the Professors evidences of the Medicine College of the Minas Gerais Federal Faculty (Faculdade de Medicina da Universidade Federal de Minas Gerais), elements are furnished to explain the rejection to the cathedra that has emerged in the interior of the College it-self. Conflits ara exploited that with-standed Professor/Physicians to Professor/ Searchers in the academical subject, considered as a struggle field of symbolical nature.

Cet article met en avant des résultats d'étude empirique. A dater de l'analyse de témoignages de ex-professeurs titulaires de la Faculté de Medicine de L 'Université Federal de Minas Gerais (Faculdade de Medicina da Universidade Federal de Minas Gerais), des éléments ont été tournis pour expliquer le refus à la chaire qui s'est émergée dans l'intérieur de la université elle-même, des contestations sont exploitées qui oposaient cathédratiques/médecins avec cathédratiques/chercheurs 
dans le champ académique, consideré come champ de luttes de nature symbolique.

Esta nota presenta resultados de pesquisa. A partir del análisis de testimonios de ex-catedráticos de la Facultad de Medicina de la Universidad Federal de Minas Gerais, se ofrecen elementos para explicar la reacción contra la cátedra que se ha producido en el interior de la misma universidad. El análisis reveló conflictos que hacían con que catedráticos/médicos se opusieran a catedráticos/pesquisadores en el campo académico, considerado como campo donde se producen luchas de naturaleza simbólica. 